\title{
Where's the Spin? A DFT Study of Mixed-Valence Cyanide-Bridged Ruthenium Polypyridines
}

\author{
German E. Pieslinger, ${ }^{\circledR *, a, b}$ Alejandro Cadranel ${ }^{\circledR a, c, d}$ and Luis M. Baraldo ${ }^{\oplus *, a, c}$ \\ ${ }^{a}$ Departamento de Química Inorgánica, Analítica y Química Física, \\ Facultad de Ciencias Exactas y Naturales, Universidad de Buenos Aires, \\ Pabellón 2, Ciudad Universitaria, C1428EHA, Buenos Aires, Argentina \\ ${ }^{b}$ CONICET, Instituto de Química y Fisicoquímica Biológicas (IQUIFIB), \\ Universidad de Buenos Aires, Junín 956, C1113AAD, Buenos Aires, Argentina \\ ${ }^{c}$ CONICET, Instituto de Química Física de Materiales, Medio Ambiente y Energía (INQUIMAE), \\ Universidad de Buenos Aires, Pabellón 2, Ciudad Universitaria, C1428EHA, \\ Buenos Aires, Argentina \\ ${ }^{d}$ Department of Chemistry and Pharmacy, Interdisciplinary Center for Molecular Materials, \\ Friedrich-Alexander Universität Erlangen-Nürnberg, Egerlandstraße 3, 91058 Erlangen, Germany
}

\begin{abstract}
This article discusses the use of density functional theory (DFT) calculations in classifying and characterizing bimetallic ruthenium mixed-valence systems in terms of their electronic localization/ delocalization degree. A standard B3LYP/LanL2DZ methodology including integral equation formalism-polarizable continuum model (IEF-PCM) solvent model is evaluated for a set of 16 nonsymmetric mixed-valence cyanide-bridged ruthenium polypyridines. This procedure reproduces well the features of the observed electronic and vibrational spectra, with better agreement for the more delocalized systems, and therefore provides an appropriate description of the electronic structures. Computed spin densities support class II or class III Robin-Day assignments and allow to quantify the electronic delocalization degree. The applied methodology yields good results due to the nature of the systems explored, which display a strong electronic coupling promoted by the cyanide-bridge and a lack of strong specific solvation effects. This procedure is not only useful in the study of ground state mixed-valence systems, but also provides a powerful insight into photoinduced mixed-valence excited states of related complexes.
\end{abstract}

Keywords: DFT calculations, ruthenium polypyridines, cyanide-bridge, electron transfer

\section{Introduction}

Mixed-valence systems have attracted the interest of chemists for more than fifty years, since they are good models for the transition states involved in electron transfer reactions and allow to study the role of the bridge in electron transfer kinetics. ${ }^{1}$ One of the main questions on this field is if the electronic structure of a given system can be described as localized or delocalized. Around this issue, a classification was proposed by Robin and Day. ${ }^{2}$ Class I encompasses those systems where interactions between the initial and final electron transfer states are negligible

*e-mail: pieslinger@qi.fcen.uba.ar; baraldo@qi.fcen.uba.ar Dedicated to Professor Henrique Toma on the occasion of his $70^{\text {th }}$ birthday or absent, and therefore can be described as completely localized. Class II includes interacting systems that still remain localized, and class III involves strongly interacting, delocalized systems. This encouraged the exploration of bimetallic systems using different bridges. Curiously, classification of the first and prototypical mixed-valence system, i.e., the Creutz-Taube ion, ${ }^{3}$ proved to be one of the most controversial. ${ }^{4-16}$

Very early, spectroscopic properties were proposed as an experimental criterion to classify mixed-valence systems. Hush's two-state model provides an easy way to extract information about the potential surfaces involved in the electron transfer from the properties of inter-valence charge transfer (IVCT) transitions for class II systems. This model assumes a weak coupling between the initial 
and final configurations of the electron transfer and hence it is of limited use for systems where the bridge promotes a strong coupling.

Cyanide is a prominent example of a bridge that promotes strong coupling and many cyanide-bridged bimetallic systems have been reported. ${ }^{17}$ However, most of them present class II characteristics. This is due to the nonsymmetric nature of the bridge, that stabilizes low oxidation state on the C-bound metal ion. The Prussian Blue polymer is a classic example of this behavior. ${ }^{18}$ Nevertheless, charge delocalization can be achieved by tuning the coordination sphere of the metal ions to compensate the lack of redox symmetry of the cyanide-bridge. The use of this strategy to achieve several class III delocalized bimetallic and trimetallic cyanide-bridged complexes has been reported recently. ${ }^{19-22}$ Despite this progress, the overall characterization of charge distribution on cyanide-bridged systems remains a challenge.

In this article we address the question of electronic localization/delocalization in cyanide-bridged $\{\mathrm{RuRu}\}$ bimetallic complexes by density functional theory (DFT) computational methods. The main limitation of DFT methods to describe open shell systems is their tendency to underestimate the energy of delocalized configurations, and hence to assign them as the ground state configuration in most cases. This is due the so-called self-interaction error (SIE). The SIE is a serious problem of most contemporary functionals, so ubiquitous that Yang and co-workers ${ }^{23-26}$ have recently introduced and defined a specific "delocalization error" in DFT. Another difficult task for DFT methods is to model the strong specific interactions of the solvent with some very popular terminal ligands as the amino (e.g., present in the Creutz-Taube ion) and the cyanide ${ }^{27,28}$ (e.g., that arises from using cyanometallates as building blocks).

In this work we show that standard DFT calculations provide an adequate description of the properties of mixed-valence cyanide-bridged complexes containing two ruthenium ions whenever they present a substantial degree of charge delocalization. When the degree of delocalization is small, this methodology still provides a qualitative description of the charge distribution across a variety of scenarios.

\section{Methodology}

Standard DFT computations were employed to fully optimize the geometries of the complexes in acetonitrile, without symmetry constraints. The geometries of the $\mathrm{Ru}^{\mathrm{II}}-\mathrm{Ru} \mathrm{u}^{\mathrm{II}}$ singlet ground state were optimized and served as the starting point for the optimization of the mixed-valence one-electron oxidized species. Calculations were done with the Gaussian09 package, ${ }^{29}$ at the B3LYP (Becke, 3-parameter, Lee-Yang-Parr) level of theory using restricted and unrestricted approximations of the Kohn-Sham equations, depending on the total number of electrons. ${ }^{30}$ In all cases, we employed the effective core potential basis set LanL2DZ (Los Alamos National Laboratory 2-double-zeta), ${ }^{31-33}$ which proved to be suitable for geometry predictions in coordination compounds containing second row transition metals. All the calculations were performed using an UltraFine grid. Solvation effects were accounted for using the most recent implementation of the implicit integral equation formalism-polarizable continuum model (IEF-PCM) solvation model. ${ }^{34-36}$ We used tight convergence criteria in the geometry optimizations and default settings for infrared (IR) calculations. All optimized structures were confirmed as minima by analyzing the harmonic vibrational frequencies. ${ }^{37}$ Vertical electronic excitation energies and intensities were evaluated using time-dependent DFT ((TD)DFT) ${ }^{38,39}$ approach with the Gaussian09 package, ${ }^{29}$ without symmetry constraints. GaussSum 2.2.6 $6^{40}$ software was used to perform spectral simulations, to extract spectral data and molecular orbital information and to obtain the electron density difference maps (EDDM). Graphical visualizations were generated by Gauss View 5.0.8, ${ }^{41}$ i.e., the isovalues were drawn at 0.004 (EDDM), 0.04 (Kohn-Sham molecular orbitals (MOs)), or 0.004 (spin-density calculations). The EDDM, the composition of electronic transitions, and the associated molecular orbitals for all the calculated complexes are shown in the Supplementary Information (SI) section. An asset of our methodology is the excellent balance between adequate descriptions of the electronic structures and low associated computational costs. In our experience, the use of lager basis sets does not lead to improved results for cyanide-bridge ruthenium polypyridine systems.

\section{Targeted molecules}

As stated above, specific solvation effects may be important in mixed-valence compounds when they involve fragments with strong solvent interactions, e.g., the popular $\left\{\mathrm{Ru}\left(\mathrm{NH}_{3}\right)_{5}\right\}$ and $\left\{\mathrm{Fe}(\mathrm{CN})_{5}\right\}$ moieties (see, for example, Aguirre-Araque et al. $^{42}$ work). In fact, for complexes exposing strong donor/acceptor ligands to the solvent, these interactions result in solvatochromism ${ }^{43-46}$ and can also lead to significant changes in the electronic structure. ${ }^{47-50}$ These specific solvation effects result challenging to model with standard DFT calculations as they are very difficult to be taken into account using implicit solvation models. ${ }^{51}$ To sort this difficulty, we have selected a molecular test set of 16 complexes where we expect these effects to be weak (Scheme 1). All these molecules involve two ruthenium 
polypyridine complexes bridged by a cyanide ligand with none to two strong donor or acceptor groups exposed to the solvent. Thus, for these systems we expect that solutesolvent interactions will be fairly reproduced using the IEF-PCM solvation model.

\section{Results and Discussion}

Non-symmetric cyanide-bridge

The non-symmetric nature of the cyanide-bridged systems has typically confined them to the class II. However, this limitation could be overcome by tuning the donor character of the ligands on the coordination sphere of both metallic ions. In 1990, Lever ${ }^{52}$ introduces an additive ligand electrochemical parameter, $\mathrm{E}_{\mathrm{L}}(\mathrm{L})$, to quantify the effect of the ligands on the observed $\mathrm{M}^{\mathrm{n}} / \mathrm{M}^{\mathrm{n}-1}$ redox potentials. This is an effective measurement of the donor character of the ligand, as a higher donor character will result in a lower redox potential. A decade later, he showed ${ }^{53,54}$ that there is a correlation between electrochemical potentials and the energy of the metal-toligand charge transfer transitions $\left(\mathrm{E}_{\max }(\mathrm{MLCT})\right)$. In fact, he stated that as an MLCT excitation effectively involves oxidation of the metal and reduction of the ligand, and since both the potentials can be written in terms of $\Sigma \mathrm{E}_{\mathrm{L}}(\mathrm{L})$, there must also be linear correlations between $\mathrm{E}_{\max }(\mathrm{MLCT})$ and metal oxidation or ligand reduction potentials, and also between $\mathrm{E}_{\max }(\mathrm{MLCT})$ and a suitable function of $\mathrm{E}_{\mathrm{L}}(\mathrm{L})$. These correlations are extensively discussed elsewhere..$^{53,54}$

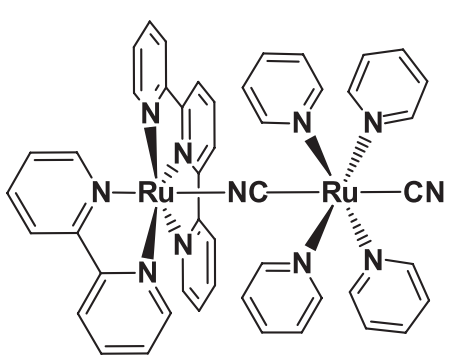

1

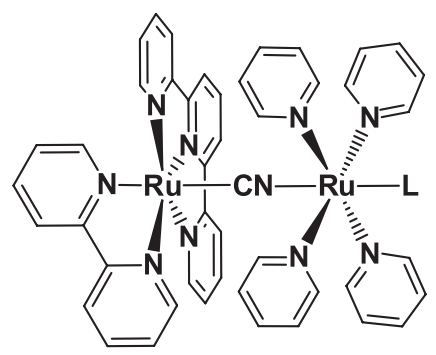

4

5

6

7

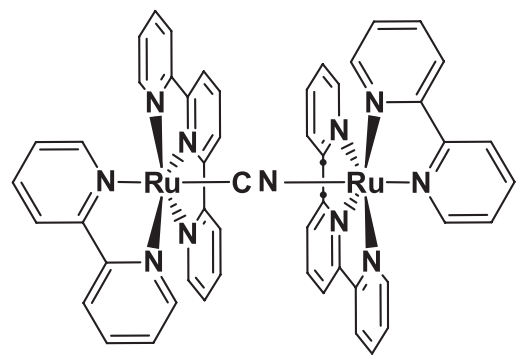

14

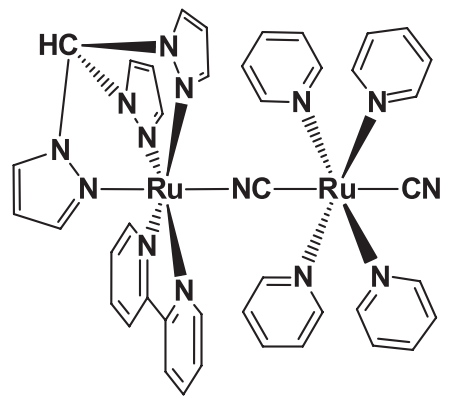

2

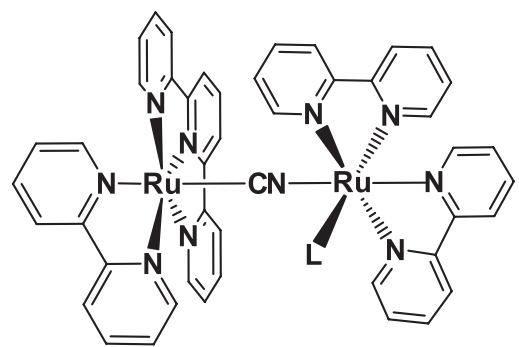

8

9

10

11

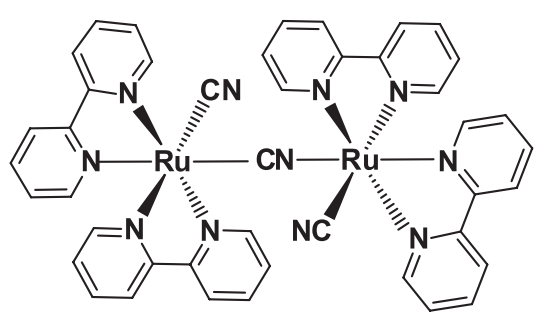

15

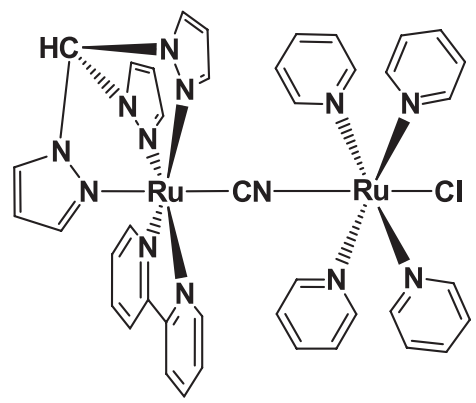

3

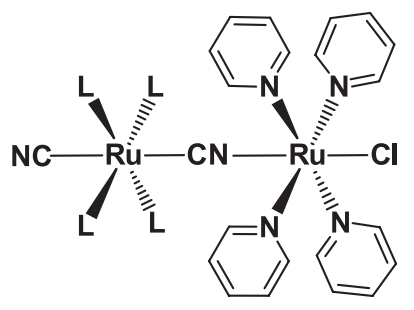

$12 \mathrm{~L}=$ MeOpy

$13 \mathrm{~L}=$ py

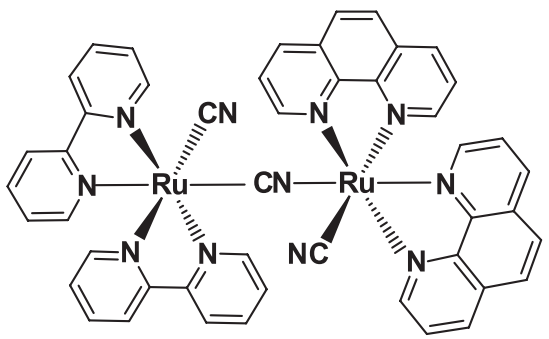

16

Scheme 1. Structure of targeted molecules (DMAP: 4-dimethylaminopyridine, MeOpy: 4-methoxypyridine, py: pyridine). 
Table 1. Lever parameters for the bimetallic complexes studied in this work

\begin{tabular}{|c|c|c|c|c|}
\hline Complex & $\Sigma \mathrm{E}_{\mathrm{L}}(\mathrm{L}) \mathrm{Ru}-\mathrm{CN}$ & $\Sigma \mathrm{E}_{\mathrm{L}}(\mathrm{L}) \mathrm{Ru}-\mathrm{NC}$ & $\Delta \mathrm{E}_{(\mathrm{RuCN}-\mathrm{RuNC})}$ & $\mathrm{E}_{\max } \mathrm{IVCT} / \mathrm{cm}^{-}$ \\
\hline $\mathbf{1}^{3+}$ & 1.020 & 1.268 & -0.248 & 6000 \\
\hline $2^{3+}$ & 1.020 & 1.208 & -0.188 & 6300 \\
\hline $4^{4+}$ & 1.268 & 1.340 & -0.072 & 6800 \\
\hline $8^{4+}$ & 1.268 & 1.376 & -0.108 & 6900 \\
\hline $12^{2+}$ & 0.820 & 0.760 & 0.060 & 7200 \\
\hline $14^{4+}$ & 1.268 & 1.268 & 0.000 & 7400 \\
\hline $16^{2+}$ & 1.056 & 1.040 & 0.016 & 7580 \\
\hline $15^{2+}$ & 1.056 & 1.056 & 0.000 & 7690 \\
\hline $9^{4+}$ & 1.268 & 1.146 & 0.122 & 8400 \\
\hline $13^{2+}$ & 1.020 & 0.760 & 0.260 & 8400 \\
\hline $5^{4+}$ & 1.268 & 1.110 & 0.158 & 8900 \\
\hline $10^{3+}$ & 1.268 & 0.976 & 0.292 & 9500 \\
\hline $6^{3+}$ & 1.268 & 0.940 & 0.328 & 9700 \\
\hline $3^{3+}$ & 1.208 & 0.760 & 0.448 & 10000 \\
\hline $7^{3+}$ & 1.268 & 0.760 & 0.508 & 10400 \\
\hline $11^{3+}$ & 1.268 & 0.796 & 0.472 & 10800 \\
\hline
\end{tabular}

$\mathrm{E}_{\mathrm{L}}(\mathrm{L})$ : additive ligand electrochemical parameter; $\mathrm{E}_{\max }$ IVCT: maximum energy of inter-valence charge transfer.

Inspired by this work, we embarked on the search of a correlation involving IVCT transitions. Table 1 presents the value of $\Sigma \mathrm{E}_{\mathrm{L}}(\mathrm{L})$ for each ruthenium center in the series studied here. Figure 1 shows a clear correlation between the IVCT maximum $\left(\mathrm{E}_{\max }(\mathrm{IVCT})\right)$ and the difference between the ruthenium redox potentials estimated using Lever parameters. The systems that present the lower energy for the IVCT transitions are those where $\Delta \mathrm{E}_{\text {(RuCN-RuNC) }}$ is negative, i.e., where the donor character of the coordination sphere of the C-bound ruthenium is higher than the donor character of the coordination sphere of the $\mathrm{N}$-bound ruthenium, compensating the imbalance of the bridge. Hence, the Lever parameters provide reliable guide to anticipate if in a given mixed-valence system the localization of the charge on one ion is favored (class II); or if the acceptor character of ions are balanced and a certain degree of delocalization is expected.

\section{Experiment-theory correlations}

Focusing now on the results of the DFT calculations, Table 2 summarizes the experimental and calculated IVCT parameters for the 16 mixed-valence complexes. It is worth to notice that we report here for the first time DFT results for complexes $\mathbf{1 2}^{2+}, \mathbf{1 3}^{2+}, \mathbf{1 4}^{4+}, \mathbf{1 5}^{2+}$ and $\mathbf{1 6}^{2+}$ (see SI section).

Figure 2 shows a correlation between the experimental and calculated E(IVCT). DFT calculations reproduce very well the observed maxima for the eight complexes with

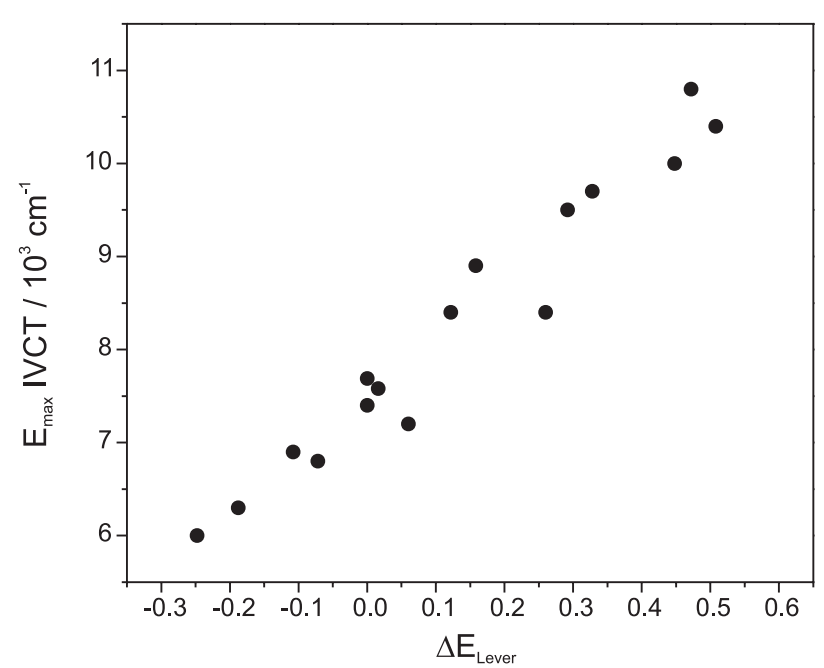

Figure 1. Correlation between $\mathrm{E}_{\max }$ IVCT and difference of ruthenium redox potentials estimated using Lever parameters.

the lower E(IVCT). For these systems, a smaller energy difference between the $\mathrm{d} \pi$ orbitals is expected, and hence these are the best candidates for delocalization. In fact, $\mathbf{1}^{3+}$, $\mathbf{2}^{3+}, \mathbf{4}^{4+}$ and $\mathbf{8}^{4+}$ have been reported as class III. ${ }^{20-22}$ In contrast, the remaining complexes are localized class II systems close to the frontier with class III. As standard DFT calculations tend to favor delocalized configurations, the more localized behavior the complex presents, the worse the agreement between the observed and the calculated properties is.

Regarding vibrational spectroscopy, DFT calculations perform acceptably at reproducing the cyanide-bridge 
Table 2. Comparison between experimental and calculated IVCT parameters (both in MeCN)

\begin{tabular}{|c|c|c|c|c|c|c|}
\hline \multirow{2}{*}{ Complex } & \multicolumn{3}{|c|}{ IVCT experimental } & \multicolumn{2}{|c|}{ IVCT calculated } & \multirow{2}{*}{ Reference } \\
\hline & $v_{\max } / \mathrm{cm}^{-1}$ & $\varepsilon_{\max } /\left(\mathrm{M}^{-1} \mathrm{~cm}^{-1}\right)$ & $\Delta v_{1 / 2} / \mathrm{cm}^{-1}$ & $v_{\max } / \mathrm{cm}^{-1}$ & f/a.u. & \\
\hline $\mathbf{1}^{3+}$ & 6000 & 7600 & 1800 & 6310 & 0.2036 & 22 \\
\hline $2^{3+}$ & 6300 & 7000 & 2000 & 6477 & 0.2611 & 22 \\
\hline $4^{4+}$ & 6800 & 6100 & 2700 & 6932 & 0.2353 & 21 \\
\hline $8^{4+}$ & 6900 & 5500 & 2900 & 6839 & 0.2456 & 20 \\
\hline $12^{2+}$ & 7200 & 8500 & 3100 & 7115 & 0.1812 & 55 \\
\hline $14^{4+}$ & 7400 & 6700 & 3600 & 7460 & 0.1814 & 56 \\
\hline $16^{2+}$ & 7580 & 10500 & 3400 & 7545 & 0.2352 & 57 \\
\hline $15^{2+}$ & 7690 & 10200 & 3400 & 7555 & 0.2248 & 57 \\
\hline $9^{4+}$ & 8400 & 4600 & 3800 & 7619 & 0.1548 & 20 \\
\hline $13^{2+}$ & 8400 & 6000 & 3400 & 7614 & 0.1377 & 55 \\
\hline $5^{4+}$ & 8900 & 7500 & 3700 & 7907 & 0.1896 & 55 \\
\hline $10^{3+}$ & 9500 & 3600 & 4500 & 8381 & 0.0764 & 20 \\
\hline $6^{3+}$ & 9700 & 4300 & 3800 & 8794 & 0.1190 & 55 \\
\hline $3^{3+}$ & 10000 & 5000 & 3100 & 9308 & 0.1681 & 58 \\
\hline $7^{3+}$ & 10400 & 3800 & 3800 & 9382 & 0.0761 & 55 \\
\hline $11^{3+}$ & 10800 & 3200 & 4700 & 9328 & 0.1003 & 20 \\
\hline
\end{tabular}

IVCT: inter-valence charge transfer; $v_{\max }$ : transition energy; $\varepsilon_{\max }$ : maximum extinction coefficient; $\Delta v_{1 / 2}$ : full width at half-maximum of the band; f: oscillator strength.

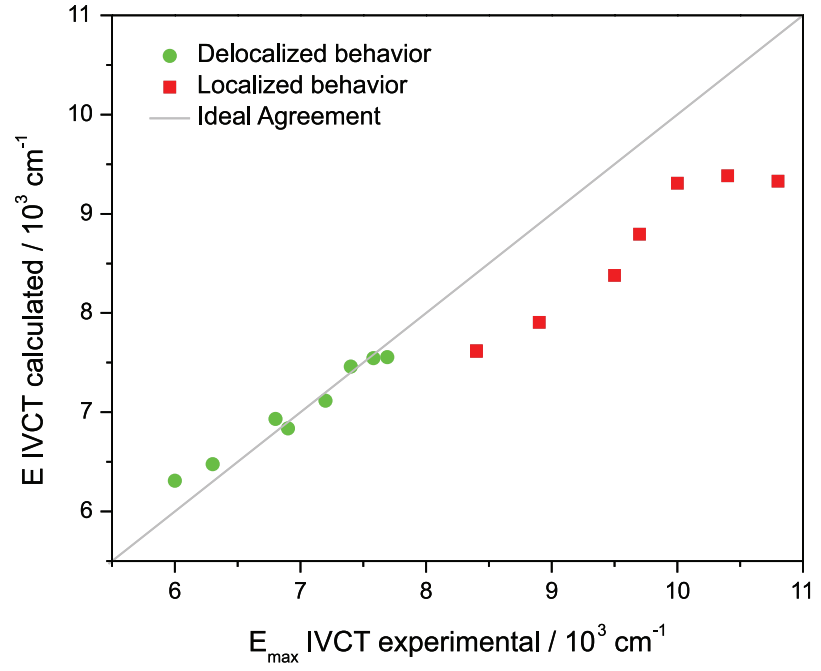

Figure 2. Correlation of calculated IVCT energies with experimental data.

stretching frequency. In all cases, only one stretch active mode is listed within $30 \mathrm{~cm}^{-1}$ error when no correction factor is applied. Table 3 lists the experimental and calculated $v_{\mathrm{C}=\mathrm{N}}$ corresponding to the bridging ligand. Again, a better agreement is found for the most delocalized systems.

Computational characterization is often difficult in open-shell mixed-valence systems, ${ }^{59}$ and the success of the standard B3LYP/LanL2DZ method in the molecules studied here is due two main reasons: (i) the systems explored here exposed to the solvent none or only a few ligands that have specific interactions with the solvent (i.e., $\mathrm{CN}^{-}$ and/or $\mathrm{NCS}^{-}$). Thus, it is expected that this effect will not
Table 3. Experimental and calculated infrared data in $\mathrm{MeCN}$

\begin{tabular}{lcc}
\hline \multirow{2}{*}{ Complex } & \multicolumn{2}{c}{$v_{\mathrm{CN}} / \mathrm{cm}^{-1}$} \\
\cline { 2 - 3 } & Experimental & Calculated \\
\hline $\mathbf{1}^{3+}$ & 2020 & 2015 \\
$\mathbf{2}^{3+}$ & 2029 & 2023 \\
$\mathbf{4}^{4+}$ & 2022 & 2015 \\
$\mathbf{8}^{4+}$ & 2032 & 2036 \\
$\mathbf{1 2}^{2+}$ & 1993 & 2012 \\
$\mathbf{1 4}^{4+}$ & N.A. & 2044 \\
$\mathbf{1 6}^{2+}$ & N.A. & 2038 \\
$\mathbf{1 5}^{2+}$ & 2015 & 2038 \\
$\mathbf{9}^{4+}$ & 2021 & 2044 \\
$\mathbf{1 3}^{2+}$ & 2004 & 2010 \\
$\mathbf{5}^{4+}$ & 2037 & 2052 \\
$\mathbf{1 0}^{3+}$ & 2022 & 2060 \\
$\mathbf{6}^{3+}$ & 2026 & 2051 \\
$\mathbf{3}^{3+}$ & 2037 & 2055 \\
$\mathbf{7}^{3+}$ & 2037 & 2047 \\
$\mathbf{1 1}^{3+}$ & 2053 & 2068 \\
\hline
\end{tabular}

N.A.: not available.

play an important role in the electronic structure; therefore, medium effects are reproduced quite well using the implicit solvation model IEF-PCM; (ii) the nature of ligand bridge: cyanide is a short, not bulky linker which allows a strong coupling between ruthenium centers by effective overlap with their $\mathrm{d} \pi$ orbitals. Added to that, the cylindric symmetry 
of cyanide precludes the existence of rotational conformers. Variations of the dihedral angle between larger bridges such as $\mu$-pz or $\mu-\mathrm{C} \equiv \mathrm{C}-\mathrm{Ph}-\mathrm{C} \equiv \mathrm{C}^{60}$ and the connected metal centers severely affect orbital overlap and hence charge distribution, leading optimizations to fall in different local minima. The simple cyanide's symmetry avoids these issues, yielding robust results. In fact, for all the bimetallic systems studied here, we run the optimizations using different starting conformational isomers and we obtain systematically the same optimized geometry and electronic structure for each compound.

Computed spin densities as quantitative assessment of electronic delocalization

Due to the good agreement between experimental and calculated transitions in both electronic and vibrational spectroscopies, we assume that our DFT calculations afford a proper description of electron density in the mixedvalence complexes presented here. In these open shell bimetallic systems, the alpha- and beta-spin orbitals are not identical and population analyses can thus be performed separately for both densities. While accumulation of alpha- and beta-spin densities over atoms still yields atomic charges, the difference between alpha- and beta-spin densities corresponds to the unpaired spin density (SD) at a given center, and the algebraic sum of all atomic SDs is equal to the number of unpaired electrons. Thus, by means of a Mulliken population analysis, it is possible to quantify the electronic delocalization in these systems.

Table 4 summarized the Mulliken spin density (MSD) calculated for each ruthenium center of the complexes studied here. Plotting the experimental $\mathrm{E}_{\max }$ (IVCT) versus ruthenium spin densities ratio yields a clear correlation: the more evenly distributed the spin densities are, the lower $\mathrm{E}_{\max }$ (IVCT) is (Figure 3); as expected using Hush's two states model.

Furthermore, analyzing the results for closed related systems (i.e., 4-7 vs. 8-11), it is clear that electronic delocalization (estimated by Mulliken SD in ruthenium centers) is mainly function of relative energy for each fragment (which one can estimated using Lever parameters and/or experimental redox potentials) and the coordination sphere's geometry does not play an important role..$^{21,57}$

While Mulliken spin densities can help us to quantify the electronic delocalization, the spin-density isosurface plots shed a light over the orientation and spatial location of the unpaired electron (or hole) in the molecule. For example, these plots were especially useful to understand the contrasting spectroscopy between the closed-related bimetallic systems $\mathbf{1}^{3+}, \mathbf{2}^{3+}$ and $\left[\mathrm{Ru}^{\mathrm{II}}\left(\mathrm{L}^{3}\right)(\mathrm{bpy})(\mu-\mathrm{NC}) \mathrm{Ru}^{\mathrm{III}}(\mathrm{MeOpy})_{4}(\mathrm{CN})\right]^{3+}$
Table 4. Computed Mulliken spin densities (MSD) for ruthenium centers

\begin{tabular}{lccc}
\hline Complex & MSD $(\mathrm{Ru}-\mathrm{CN})$ & $\mathrm{MSD}(\mathrm{Ru}-\mathrm{NC})$ & $\mathrm{MSD}_{\mathrm{Ru}-\mathrm{NC}} / \mathrm{MSD}_{\mathrm{Ru}-\mathrm{CN}}$ \\
\hline $\mathbf{1}^{3+}$ & 0.41 & 0.55 & 1.34 \\
$\mathbf{2}^{3+}$ & 0.45 & 0.49 & 1.09 \\
$\mathbf{4}^{4+}$ & 0.49 & 0.46 & 0.94 \\
$\mathbf{8}^{++}$ & 0.35 & 0.59 & 1.69 \\
$\mathbf{1 2}^{2+}$ & 0.26 & 0.68 & 2.62 \\
$\mathbf{1 4}^{4+}$ & 0.20 & 0.72 & 3.60 \\
$\mathbf{1 6}^{2+}$ & 0.28 & 0.67 & 2.39 \\
$\mathbf{1 5}^{2+}$ & 0.27 & 0.68 & 2.52 \\
$\mathbf{9}^{4+}$ & 0.17 & 0.74 & 4.35 \\
$\mathbf{1 3}^{2+}$ & 0.18 & 0.75 & 4.17 \\
$\mathbf{5}^{4+}$ & 0.11 & 0.73 & 6.64 \\
$\mathbf{1 0}^{3+}$ & 0.08 & 0.70 & 8.75 \\
$\mathbf{6}^{3+}$ & 0.10 & 0.70 & 7.00 \\
$\mathbf{3}^{3+}$ & 0.13 & 0.79 & 6.08 \\
$\mathbf{7}^{3+}$ & 0.11 & 0.81 & 7.36 \\
$\mathbf{1 1}^{3+}$ & 0.08 & 0.81 & 10.13 \\
\hline
\end{tabular}

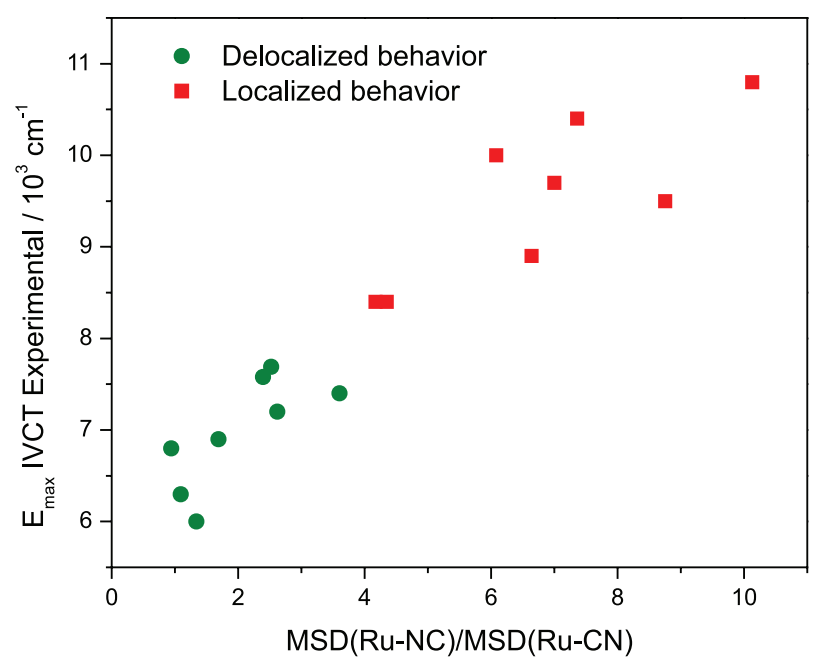

Figure 3. Correlation of experimental IVCT energies with ruthenium Mulliken spin densities ratio.

$\left(\mathrm{L}^{3}=\right.$ terpyridine (tpy) or tris(pyrazolyl)methane (tpm)). The MeOpy (4-methoxypyridine) complexes show the expected low energy IVCT transitions at 6000 and $7000 \mathrm{~cm}^{-1}$, but with an anomalously weak intensity. Computed Mulliken spin densities for each ruthenium classified $\mathbf{1}^{3+}$ and $\mathbf{2}^{3+}$ as delocalized $\left(\mathrm{MSD}_{\mathrm{Ru}-\mathrm{NC}} / \mathrm{MSD}_{\mathrm{Ru}-\mathrm{CN}}\right.$ of 1.34 and 1.09 , respectively), while the MeOpy analogues are localized ( $<<0.01$ for both, i.e., completely localized in RuCN center). ${ }^{22}$ The latter result seems to be at odds with the observed low energy for the IVCT transitions. Explanation for this apparent contradiction can be found in the comparison between the spin-density isosurface plots (Figure 4) for $2^{3+}$ and $\left[\mathrm{Ru}^{\mathrm{II}}(\mathrm{tpm})(\mathrm{bpy})(\mu-\mathrm{NC}) \mathrm{Ru}^{\mathrm{III}}(\mathrm{MeOpy})_{4}(\mathrm{CN})\right]^{3+}$. While in the former the hole is evenly distributed between the two ruthenium ions, in the latter the hole it is not only localized 

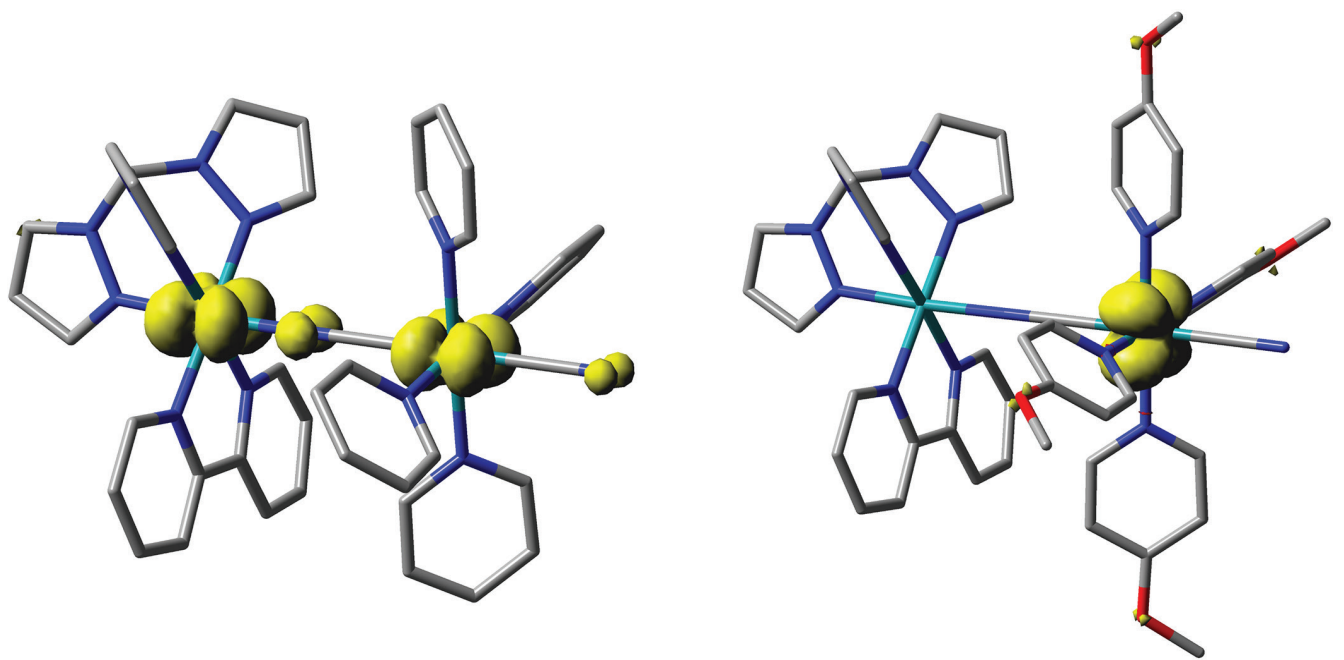

Figure 4. Spin density isosurface plot $\left(0.004\right.$ a.u.) for $\mathbf{2}^{3+}$ (left) and $\left[\mathrm{Ru}^{\mathrm{II}}(\mathrm{tpm})(\mathrm{bpy})(\mu-\mathrm{NC}) \mathrm{Ru}^{\mathrm{II}}(\mathrm{MeOpy})_{4}(\mathrm{CN})\right]^{3+}$ (right) in $\mathrm{MeCN}$ showing different orientation of unpaired electron.

but also sits perpendicular to the intermetallic axis. This minimizes the wavefunction overlap with the cyanide-bridge and with the other metal center, leading to weak electronic IVCT transitions in the MeOpy analogues. ${ }^{22}$

\section{Electronic coupling estimations and free-energy surfaces}

Despite its limitations, the Hush's standard two-states model is still widely used in the classification of new systems. One of the most important parameters obtained by this model is the degree of electronic coupling between donor an acceptor sites, $\mathrm{H}_{\mathrm{ab}}$, which can be determined from IVCT transitions. For symmetrical class III systems, $\mathrm{H}_{\mathrm{ab}}$ is one half of the transition's energy; and for symmetrical class II systems, it can be calculated using Hush's formula:

$\mathrm{H}_{\mathrm{ab}}=\frac{2.06 \times 10^{2} \sqrt{\bar{v} \times \Delta \bar{v}_{1 / 2} \times \varepsilon_{\max }}}{\mathrm{r}_{\mathrm{ab}}}$

where $\bar{v}$ is the energy of the transition, $\Delta \bar{v}_{1 / 2}$ its full width at half-maximum of the band, $\varepsilon_{\max }$ its maximum extinction coefficient, and $r_{a b}$ is the donor-acceptor distance (usually assumed as metal-metal distance).

Hush's formula proves to be useful only when applied in weakly coupled class II systems. For strongly coupled systems with some degree of charge delocalization, this formula heavily underestimates the electronic coupling degree. For these systems, delocalization results in a smaller charge transferred $(\Delta \mathrm{e})$ across a distance other than the geometric metal-metal distance, hence $\mathrm{er}_{\mathrm{ab}}$ is a poor approximation for the change in dipole moment. ${ }^{61,62}$

Moreover, Meyer and co-workers ${ }^{63}$ have pointed out that assessing the extent of electronic delocalization though analysis of the IVCT absorption bands that typically appear in the near-IR spectra must be done carefully. The multiple ligand-mediated orbital interactions in transitionmetal complexes can result in multiple intervalence (IT) transitions split by low symmetry and spin-orbit coupling. ${ }^{64}$ For $\mathrm{d} \pi^{6}-\mathrm{d} \pi^{5}$ systems, in particular, this gives rise to five low-energy transitions, three of IT origin and two of interconfigurational (IC) origin, as depicted in Scheme 2.

Interestingly, despite the standard B3LYP/LanL2DZ employed do not include any spin-orbit coupling effect, (TD)DFT results show these spectroscopic features: in all cases, the first five low-energy electronic transitions have IC + IT character as revealed by the EDDM calculated for each transition. This suggests that the low symmetry of these bimetallic complexes is enough to split the $\mathrm{d} \pi$ orbitals by ligand field effects. Due to the moderate spin-orbit coupling expected for ruthenium ions and mainly because of the broad width of each IT transition, in most of the cases, the multiple IVCT bands are not resolved experimentally. Nevertheless, for delocalized and in-borderline systems the structure of the IVCT bands can be observed as each IT band becomes narrower, sharper and more intense while

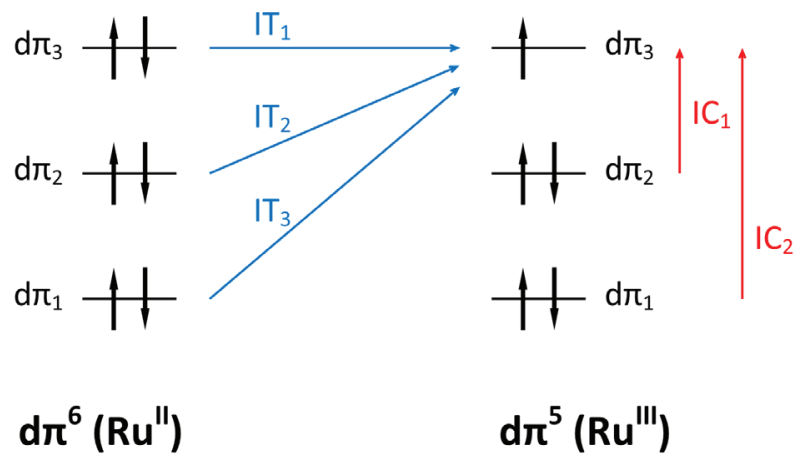

Scheme 2. IT and IC transitions in $d \pi^{6}-\mathrm{d} \pi^{5}$ mixed-valence systems such as $\mathrm{Ru}^{\mathrm{II}}-\mathrm{L}-\mathrm{Ru}^{\mathrm{III}}$ complexes. 
shifting to lower energies. Meyer and co-workers ${ }^{63}$ reported one of the first clear examples of this spectroscopy pattern. We observed the same feature in the delocalized bimetallic systems $\mathbf{1}^{3+}, \mathbf{2}^{3+}, \mathbf{4}^{4+}, \mathbf{8}^{4+}$ and $\mathbf{1 2}^{2+}$. For them, (TD)DFT reproduces remarkably well the energy of the electronic transitions in the near-infrared (NIR) region, but in some cases fails to reproduce the energy of transitions that are observed in the infrared..$^{20-22}$ This suggests that spin-orbit coupling plays an important role in latter transitions. As our calculations do not contemplate this effect, the calculated energy for these transitions may not be reliable.

Nevertheless, for each bimetallic complex studied here, the most intense calculated electronic transition correlates with the energy of the IVCT band's maximum. In all these cases, the EDDM (a representation of the changes in electron density that occur for a given electronic transition) indicated that the most intense transition involves states spread over the intermetallic axis (e.g., Figure 5).

Through this report, we use the IVCT nomenclature for historical reasons, but no real charge transfer is expected in delocalized class III systems. Note that the optical transition in a symmetrical class III system, although intense, no longer involves a net charge transfer and is therefore not accompanied by a net dipole-moment change. Consequently, it should show no solvent dependence. Instead, the optical absorption involves transitions between delocalized molecular orbitals of the system. Figure 5 illustrates this phenomenon: $\mathbf{1 3}^{2+}$ is a clear example of a class II complex where electron density migrates from one ruthenium ion to the other during the electronic transition. In contrast, for $\mathbf{2}^{3+}$ the EDDM indicates that there is nearly no electronic redistribution involved during transition (i.e., no charge transfer). This result is supported by the fact that the IVCT transition does not depend on the nature of the solvent in experimental measurements. Moreover, SD for $\mathbf{2}^{3+}$ shows an even spin distribution over the two ruthenium centers. Thus, despite the geometrical

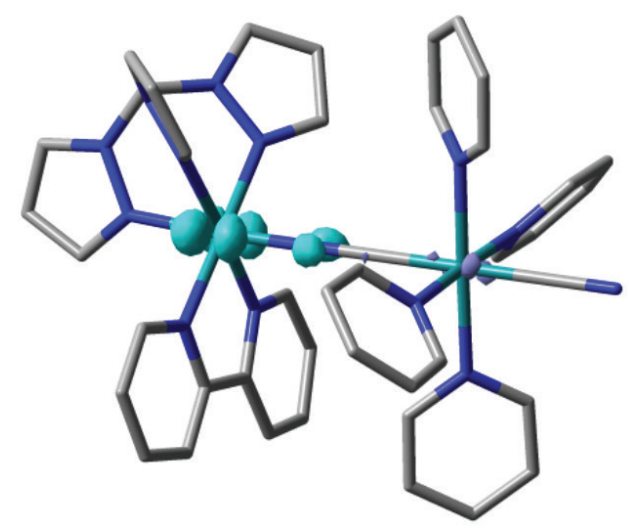

asymmetry, we classified this system as a class III system with an estimate $\mathrm{H}_{\mathrm{ab}}$ value of $3150 \mathrm{~cm}^{-1}$. Similar $\mathrm{H}_{\mathrm{ab}}$ values have been calculated from Stark measurements ${ }^{61,62}$ for other mixed-valence complexes sharing the $\left\{\mathrm{Ru}^{\mathrm{II}}-\mathrm{CN}-\mathrm{Ru}^{\mathrm{III}}\right\}$ motif; hence, comparable values are expected for all the complexes reported here.

For non-symmetrical class II systems where an energetic difference $\left(\Delta \mathrm{G}_{0}\right)$ between the sites exists, the thermal electron transfer barrier $\left(\Delta \mathrm{G}_{\mathrm{th}}^{*}\right)$ is given by:

$\Delta \mathrm{G}_{\mathrm{th}}^{*}=\frac{\left(\lambda+\Delta \mathrm{G}_{0}\right)^{2}}{4 \lambda}-\mathrm{H}_{\mathrm{ab}}$

being $\lambda$ the reorganizational energy. ${ }^{65}$ Thus, the large $\mathrm{H}_{\mathrm{ab}}$ value probably erases the thermal barrier between the two adiabatic configurations for the electronic isomers in the remaining mixed-valence systems discussed here. In other words, they can be described as strongly coupled class II systems, with a free energy surface showing only one minimum. This minimum is not equidistant to both diabatic minima due to the difference in the coordination spheres between the metal centers $\left(\Delta \mathrm{G}_{0}\right)$; hence, these systems present a localized charge distribution. A similar model has been proposed ${ }^{66}$ for $\left\{\mathrm{Ru}^{\mathrm{II}}-\mathrm{NC}-\mathrm{Fe}^{\mathrm{III}}\right\}$ and $\left\{\mathrm{Ru}^{\mathrm{II}}-\mathrm{NC}-\mathrm{Os}{ }^{\mathrm{II}}\right\}$ systems based on their spectroscopic properties.

While Hush's formula has proved to be useful in study of weak coupled systems, its application in strong coupled ones may be misleading. Still, for decades it has been used in such systems with caution. Fine examples are $\mathbf{1 5}^{2+}$ and $\mathbf{1 6}^{2+}$ where Bignozzi et al..$^{57,67}$ uses Hush's model to estimate $\mathrm{H}_{\mathrm{ab}}\left(2000 \mathrm{~cm}^{-1}\right)$ and the degree of delocalization $\alpha^{2}(7 \%)$ in these complexes but, for a practical point of view, they considered them as essentially valence-localized species. However, they place a disclaimer noting that spectroscopy in different solvents suggests a strong electronic delocalization. Our DFT calculations

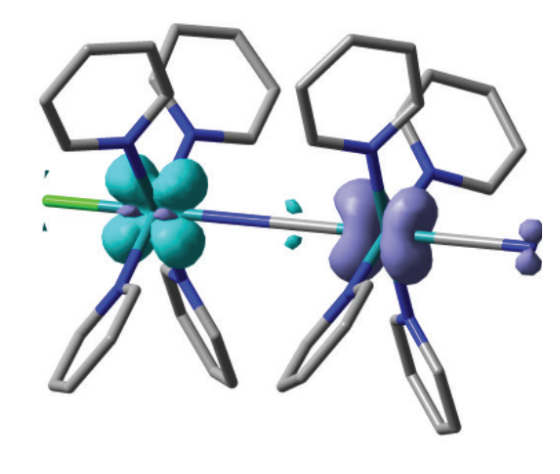

Figure 5. EDDM (0.004 a.u.) of the most intense NIR transition for the doublets $\mathbf{2}^{3+}$ (left) and $\mathbf{1 3}^{2+}$ (right) ions calculated in MeCN. Purple indicates a decrease in charge density, while cyan indicates an increase. 
prove this hypothesis right. MSD and SD isosurface plots (Table 4 and Figure S3 (SI section), respectively) indicate a significant spin delocalization in both systems, which allow us to classify them as strongly coupled class II near to the class III frontier. Similar DFT results for $\mathbf{1 2}^{2+}$ and $1 \mathbf{1 4}^{4+}$ put these systems in the same classification. Table S6 (SI section) summarizes the $\mathrm{H}_{\mathrm{ab}}$ and $\alpha^{2}$ values for all mixed-valence complexes studied here, while Figure S9 (SI section) displays plots of these values versus ruthenium Mulliken spin densities ratio or experimental IVCT energies. No trend or correlation was found, which supports our argument about MSD being a better indicator of electronic delocalization than $\mathrm{H}_{\mathrm{ab}}$ and $\alpha^{2}$ when multiple IVCT transitions are expected.

\section{Photoinduced mixed-valence systems}

The procedures mentioned above are also useful to analyze the configuration of photoinduced mixed-valence (PIMV) systems. In bimetallic cyanide-bridged ruthenium polypyridines with a $(\mathrm{d} \pi)^{6}(\mathrm{~d} \pi)^{6}$ configuration, MLCT light absorption produces transient PIMV species with a triplet multiplicity, where the properties of the photogenerated $(\mathrm{d} \pi)^{6}(\mathrm{~d} \pi)^{5}$ mixed-valence core are modulated by the presence of the polypyridine radical anion. ${ }^{68}$ It is well known that the intersystem crossing process that leads from the singlet to the triplet MLCT manifold of ruthenium polypyridines is downhill and takes around $100 \mathrm{fs} .{ }^{69,70}$ Therefore, the photoinduced IVCT (PIIVCT) bands observed using picosecond transient absorption spectroscopy techniques correspond to triplet excited states. DFT optimizations of the lowest-lying triplet state for ${ }^{3}\left(\mathbf{7}^{2+}\right)^{*},{ }^{3}\left(\mathbf{2}^{2+}\right)^{*}$ and ${ }^{3}\left(\left[\mathrm{Ru}^{\mathrm{II}}(\mathrm{tpm})(\mathrm{bpy})(\mu-\mathrm{NC}) \mathrm{Ru}^{\mathrm{II}}(\mathrm{MeOpy})_{4}(\mathrm{CN})\right]^{2+}\right) *$ yielded, in fact, PIMV systems..$^{71,72}$ There, PIIVCT transitions at 6900, 8095 and $7263 \mathrm{~cm}^{-1}$ are calculated, respectively. These values nicely agree with those experimentally observed at 6900,8800 and $8100 \mathrm{~cm}^{-1}$, respectively, using ultrafast transient absorption spectroscopy. SD isosurface plots clearly show the mixed-valence character of these systems, that in contrast to the ground-state analogues, also include spin density over the polypyridinic ligand corresponding to the radical anion (see Figure 6 and works of Oviedo et al. ${ }^{71}$ and Aramburu-Trošelj et al.). ${ }^{72}$ This allows to unambiguously identify these states as MLCT instead of metal-centered (MC) states that only show spin density over metal centers. ${ }^{73}$ Moreover, these diruthenium systems show substantial delocalization of the charge..$^{71,72}$ Currently, we are studying other bimetallic ruthenium polypyridines combining ultrafast transient absorption spectroscopy and DFT calculations in order to exploit their unique properties.

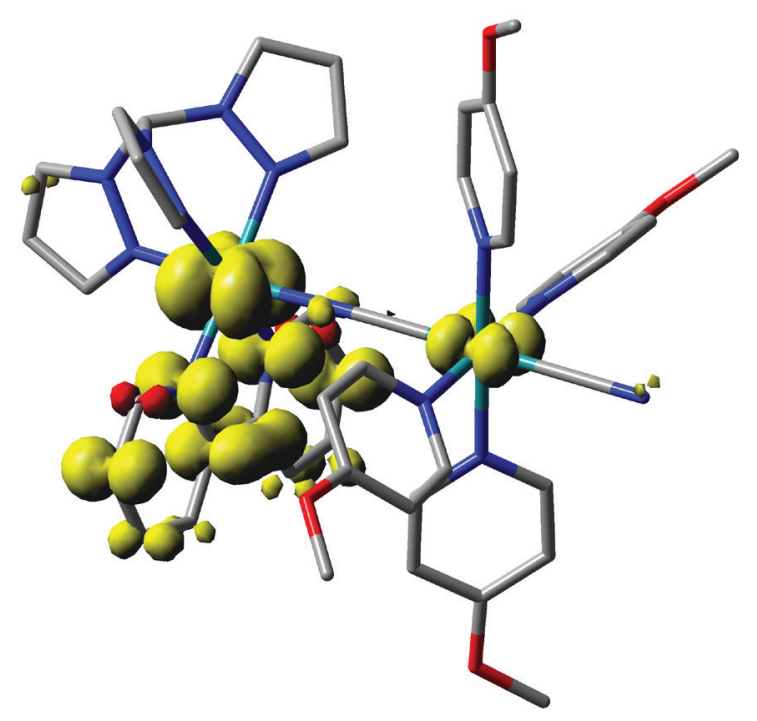

Figure 6. Spin density isosurface plot (0.004 a.u.) for the lowest-lying triplet state of $\left[\mathrm{Ru}^{\mathrm{II}}(\mathrm{tpm})(\mathrm{bpy})(\mu-\mathrm{NC}) \mathrm{Ru}^{\mathrm{II}}(\mathrm{MeOpy})_{4}(\mathrm{CN})\right]^{2+}$ ion in DMSO.

\section{Conclusions}

Standard B3LYP/LanL2DZ method proves to be a useful and robust procedure in the study of mixed-valence cyanide-bridged ruthenium polypyridines. These systems can be analyzed using this approach due to the strong electronic coupling promoted by the cyanide-bridge and in the fact that strong specific solvation effects are absent in the studied molecules. (TD)DFT calculations show very good agreement with experimental spectra. These results even reproduce the NIR band structure present in the class III systems. MSD and SD isosurface plots are proposed as clear indicators of electronic delocalization where Hush's model cannot be used. The application of the same methodology to the photoinduced mixed-valence excited states of cyanide-bridged complexes reproduces the observed transient absorption spectroscopy and gives access to the electronic distribution on these excited states.

\section{Supplementary Information}

Supplementary information is available free of charge at http://jbcs.sbq.org.br as PDF file.

\section{Acknowledgments}

This work was partially supported by the University of Buenos Aires, CONICET (PIP 0659) and ANPCyT (PICT2017-1018). G. E. P., A. C. and L. M. B. are members of the scientific staff of CONICET. G. E. P. thanks Prof Dr Adrián Roitberg for selflessly sharing his knowledge and DAAD for personal funding. A. C. acknowledges membership of ALN. 


\section{References}

1. Rocha, R. C.; Toma, H. E.; Quim. Nova 2002, 25, 624.

2. Robin, M. B.; Day, P. In Advances in Inorganic Chemistry and Radiochemistry, vol. 10; Academic Press: New York, 1968, p. 247-422.

3. Creutz, C.; Taube, H.; J. Am. Chem. Soc. 1969, 91, 3988.

4. Zhang, L. T.; Ko, J.; Ondrechen, M. J.; J. Am. Chem. Soc. 1987, 109, 1666.

5. Bolvin, H.; Inorg. Chem. 2007, 46, 417.

6. Ondrechen, M. J.; Ko, J.; Zhang, L. T.; J. Am. Chem. Soc. 1987, 109, 1672.

7. Petrov, V.; Hupp, J. T.; Mottley, C.; Mann, L. C.; J. Am. Chem. Soc. 1994, 116, 2171.

8. Krausz, E.; Chem. Phys. Lett. 1985, 120, 113.

9. Fuerholz, U.; Buergi, H. B.; Wagner, F. E.; Stebler, A.; Ammeter, J. H.; Krausz, E.; Clark, R. J. H.; Stead, M. J.; Ludi, A.; J. Am. Chem. Soc. 1984, 106, 121.

10. Todorova, T.; Delley, B.; Inorg. Chem. 2008, 47, 11269.

11. Piepho, S. B.; J. Am. Chem. Soc. 1990, 112, 4197.

12. Reimers, J. R.; Wallace, B. B.; Hush, N. S.; Philos. Trans. R. Soc., A 2008, 366, 15.

13. Reimers, J. R.; Cai, Z.-L.; Hush, N. S.; Chem. Phys. 2005, 319, 39.

14. Lu, H.; Petrov, V.; Hupp, J. T.; Chem. Phys. Lett. 1995, 235 , 521.

15. Best, S. P.; Clark, R. J. H.; McQueen, R. C. S.; Joss, S.; J. Am. Chem. Soc. 1989, 111, 548.

16. Bencini, A.; Ciofini, I.; Daul, C. A.; Ferretti, A.; J. Am. Chem. Soc. 1999, 121, 11418.

17. Endicott, J. F.; Chen, Y.-J.; Coord. Chem. Rev. 2013, 257, 1676.

18. Robin, M. B.; Inorg. Chem. 1962, 1, 337.

19. Pieslinger, G. E.; Alborés, P.; Slep, L. D.; Baraldo, L. M.; Angew. Chem., Int. Ed. 2014, 53, 1293.

20. Oviedo, P. S.; Pieslinger, G. E.; Cadranel, A.; Baraldo, L. M.; Dalton Trans. 2017, 46, 15757.

21. Domínguez, S. E.; Pieslinger, G. E.; Sanchez-Merlinsky, L.; Baraldo, L. M.; Dalton Trans. 2020, 49, 4125.

22. Pieslinger, G. E.; Aramburu-Trošelj, B. M.; Cadranel, A.; Baraldo, L. M.; Inorg. Chem. 2014, 53, 8221.

23. Mori-Sánchez, P.; Cohen, A. J.; Yang, W.; J. Chem. Phys. 2006, 125, 201102.

24. Johnson, E. R.; Mori-Sánchez, P.; Cohen, A. J.; Yang, W.; J. Chem. Phys. 2008, 129, 204112.

25. Cohen, A. J.; Mori-Sanchez, P.; Yang, W.; Science 2008, 321, 792.

26. Heaton-Burgess, T.; Yang, W.; J. Chem. Phys. 2010, 132, 234113.

27. Toma, H. E.; Takasugi, M. S.; J. Solution Chem. 1983, $12,547$.

28. Toma, H. E.; Takasugi, M. S.; J. Solution Chem. 1989, 18, 575.

29. Frisch, M. J.; Trucks, G. W.; Schlegel, H. B.; Scuseria, G. E.;
Robb, M. A.; Cheeseman, J. R.; Scalmani, G.; Barone, V.; Mennucci, B.; Petersson, G. A.; Nakatsuji, H.; Caricato, M.; Li, X.; Hratchian, H. P.; Izmaylov, A. F.; Bloino, J.; Zheng, G.; Sonnenberg, J. L.; Hada, M.; Ehara, M.; Toyota, K.; Fukuda, R.; Hasegawa, J.; Ishida, M.; Nakajima, T.; Honda, Y.; Kitao, O.; Nakai, H.; Vreven, T.; Montgomery Jr., J. A.; Peralta, J. E.; Ogliaro, F.; Bearpark, M.; Heyd, J. J.; Brothers, E.; Kudin, K. N.; Staroverov, V. N.; Keith, T.; Kobayashi, R.; Normand, J.; Raghavachari, K.; Rendell, A.; Burant, J. C.; Iyengar, S. S.; Tomasi, J.; Cossi, M.; Rega, N.; Millam, J. M.; Klene, M.; Knox, J. E.; Cross, J. B.; Bakken, V.; Adamo, C.; Jaramillo, J.; Gomperts, R.; Stratmann, R. E.; Yazyev, O.; Austin, A. J.; Cammi, R.; Pomelli, C.; Ochterski, J. W.; Martin, R. L.; Morokuma, K.; Zakrzewski, V. G.; Voth, G. A.; Salvador, P.; Dannenberg, J. J.; Dapprich, S.; Daniels, A. D.; Farkas, O.; Foresman, J. B.; Ortiz, J. V.; Cioslowski, J.; Fox, D. J.; Gaussian 09, Revision D.01; Gaussian Inc., Wallingford, CT, USA, 2013.

30. Szabo, A.; Ostlund, N. S.; Modern Quantum Chemistry: Introduction to Advanced Electronic Structure Theory; McGraw-Hill: New York, 1996.

31. Wadt, W. R.; Hay, P. J.; J. Chem. Phys. 1985, 82, 284.

32. Dunning, T. H.; Hay, P. J. In Methods of Electronic Structure Theory; Schaefer, H. F., ed.; Springer US: Boston, MA, USA, 1977, p. 1-27.

33. Hay, P. J.; Wadt, W. R.; J. Chem. Phys. 1985, 82, 299.

34. Scalmani, G.; Frisch, M. J.; J. Chem. Phys. 2010, 132, 114110.

35. Tomasi, J.; Mennucci, B.; Cammi, R.; Chem. Rev. 2005, 105, 2999.

36. Miertuš, S.; Scrocco, E.; Tomasi, J.; Chem. Phys. 1981, 55, 117.

37. Schlegel, H. B.; J. Comput. Chem. 1982, 3, 214.

38. Petit, L.; Maldivi, P.; Adamo, C.; J. Chem. Theory Comput. 2005, 1, 953 .

39. Stratmann, R. E.; Scuseria, G. E.; Frisch, M. J.; J. Chem. Phys. 1998, 109, 8218.

40. O’Boyle, N. M.; Tenderholt, A. L.; Langner, K. M.; J. Comput. Chem. 2008, 29, 839.

41. Dennington, R.; Keith, T.; Millam, J.; GaussView, version 5; Semichem, Inc., Shawnee Mission, KS, USA, 2009.

42. Aguirre-Araque, J. S.; Rocha, R. C.; Toma, H. E.; J. Coord. Chem. 2018, 71, 1778.

43. Glöckle, M.; Katz, N. E.; Ketterle, M.; Kaim, W.; Inorg. Chim. Acta 2002, 336, 55.

44. Curtis, J. C.; Sullivan, B. P.; Meyer, T. J.; Inorg. Chem. 1983, 22, 224.

45. Dodsworth, E. S.; Hasegawa, M.; Bridge, M.; Linert, W. In Comprehensive Coordination Chemistry II; McCleverty, J. A.; Meyer, T. J., eds.; Elsevier: Oxford, 2003, p. 351-365.

46. D'Alessandro, D. M.; Topley, A. C.; Davies, M. S.; Keene, F. R.; Chem. - Eur. J. 2006, 12, 4873.

47. Hupp, J. T.; Neyhart, G. A.; Meyer, T. J.; J. Am. Chem. Soc. 1986, 108, 5349. 
48. Al-Noaimi, M.; Yap, G. P. A.; Crutchley, R. J.; Inorg. Chem. 2004, 43,1770 .

49. Rossi, M. B.; Abboud, K. A.; Alborés, P.; Baraldo, L. M.; Eur. J. Inorg. Chem. 2010, 2010, 5613 .

50. Rossi, M. B.; Alborés, P.; Baraldo, L. M.; Inorg. Chim. Acta 2011, 374, 334.

51. González-Lebrero, M. C.; Turjanski, A. G.; Olabe, J. A.; Estrin, D. A.; J. Mol. Model. 2001, 7, 201.

52. Lever, A. B. P.; Inorg. Chem. 1990, 29, 1271.

53. Lever, A. B. P.; Dodsworth, E. S. In Inorganic Electronic Structure and Spectroscopy, vol. II; John Wiley \& Sons: New York, 1999, p. 227-290.

54. Lever, A. B. P. In Comprehensive Coordination Chemistry II; McCleverty, J. A.; Meyer, T. J., eds.; Elsevier: Oxford, 2003, p. 251-268.

55. Pieslinger, G. E.; Alborés, P.; Slep, L. D.; Coe, B. J.; Timpson, C. J.; Baraldo, L. M.; Inorg. Chem. 2013, 52, 2906.

56. Tsai, C.-N.; Allard, M. M.; Lord, R. L.; Luo, D.-W.; Chen, Y.-J.; Schlegel, H. B.; Endicott, J. F.; Inorg. Chem. 2011, 50, 11965.

57. Bignozzi, C. A.; Argazzi, R.; Schoonover, J. R.; Gordon, K. C.; Dyer, R. B.; Scandola, F.; Inorg. Chem. 1992, 31, 5260.

58. Oviedo, P. S.: Acoplamiento Electrónico en el Estado Excitado de Polipiridinas de Rutenio Puenteadas por Cianuro y su Rol en Procesos de Catálisis y Transferencia de Energia; $\mathrm{PhD}$ thesis, Universidad de Buenos Aires, Buenos Aires, Argentina, 2018, available at http://hdl.handle.net/20.500.12110/tesis_n6336_ Oviedo, accessed in June 2020.

59. Cohen, A. J.; Mori-Sánchez, P.; Yang, W.; Chem. Rev. 2012, 112, 289.

60. Parthey, M.; Gluyas, J. B. G.; Fox, M. A.; Low, P. J.; Kaupp, M.; Chem. - Eur. J. 2014, 20, 6895.
61. Vance, F. W.; Karki, L.; Reigle, J. K.; Hupp, J. T.; Ratner, M. A.; J. Phys. Chem. A 1998, 102, 8320.

62. Vance, F. W.; Slone, R. V.; Stern, C. L.; Hupp, J. T.; Chem. Phys. 2000, 253, 313.

63. Rocha, R. C.; Rein, F. N.; Jude, H.; Shreve, A. P.; Concepcion, J. J.; Meyer, T. J.; Angew. Chem., Int. Ed. 2008, 47, 503.

64. Demadis, K. D.; Hartshorn, C. M.; Meyer, T. J.; Chem. Rev. 2001, 101, 2655.

65. Creutz, C. In Progress in Inorganic Chemistry, vol. 30; Lippard, S. J., ed.; John Wiley \& Sons, Inc.: New York, 1983, p. 1-73.

66. Alborés, P.; Rossi, M. B.; Baraldo, L. M.; Slep, L. D.; Inorg. Chem. 2006, 45, 10595.

67. Bignozzi, C. A.; Roffia, S.; Chiorboli, C.; Davila, J.; Indelli, M. T.; Scandola, F.; Inorg. Chem. 1989, 28, 4350.

68. Aramburu-Trošelj, B. M.; Oviedo, P. S.; Ramírez-Wierzbicki, I.; Baraldo, L. M.; Cadranel, A.; Chem. Commun. 2019, 55, 7659.

69. Chergui, M.; Dalton Trans. 2012, 41, 13022.

70. Damrauer, N. H.; Science 1997, 275, 54.

71. Oviedo, P. S.; Pieslinger, G. E.; Baraldo, L. M.; Cadranel, A.; Guldi, D. M.; J. Phys. Chem. C 2019, 123, 3285.

72. Aramburu-Trošelj, B. M.; Oviedo, P. S.; Pieslinger, G. E.; Hodak, J. H.; Baraldo, L. M.; Guldi, D. M.; Cadranel, A.; Inorg. Chem. 2019, 58, 10898.

73. Cadranel, A.; Pieslinger, G. E.; Tongying, P.; Kuno, M. K.; Baraldo, L. M.; Hodak, J. H.; Dalton Trans. 2016, 45, 5464.

Submitted: March 3, 2020

Published online: July 3, 2020 